\title{
A case of cryptogenic organizing pneumonia occurring in Crohn's disease
}

\author{
Pierluigi Carratù MD ${ }^{1}$, Silvano Dragonieri $M D^{1}$, Maria Cristina Nocerino MD¹, Senia Maria Rosaria Trabucco MD², \\ Donato Lacedonia MD¹, Giuseppe Parisi MD², Onofrio Resta MD ${ }^{1}$
}

P Carratù, S Dragonieri, MC Nocerino, et al. A case of cryptogenic organizing pneumonia occurring in Crohn's disease. Can Respir J 2005;12(8):437-439.

A 29 year-old-man with Crohn's disease, who developed diffuse pulmonary infiltrates and hypoxemia two months following oral administration of mesalazine, was examined. Clinical findings and computed tomography were suggestive of, and lung histology was diagnostic of, bronchiolitis obliterans organizing pneumonia, also known as cryptogenic organizing pneumonia. Although the data did not allow for definitive conclusions, they did suggest that the pulmonary disease was an extraintestinal manifestation of Crohn's disease, rather than an adverse reaction to mesalazine. In fact, the patient showed clinical, radiological and functional improvements, despite the treatment with mesalazine and the withdrawal of steroid therapy.

Key Words: BOOP; COP; Crohn's disease; Mesalazine; Steroids

\section{Un cas de pneumonie organisée cryptogénique en présence d'une maladie de Crohn}

Est examiné un homme de 29 ans atteint de la maladie de Crohn qui a développé des infiltrats pulmonaire diffus et une hypoxémie deux mois après l'administration orale de mésalazine. Les observations cliniques et la tomodensitométrie laissaient supposer une bronchiolite oblitérante avec organisation pneumonique, également désignée pneumopathie organisée cryptogénique, diagnostiquée par une histologie pulmonaire. Bien que les données n'aient pas permis de tirer des conclusions définitives, elles indiquaient que la maladie pulmonaire constituait une manifestation extraintestinale de la maladie de Crohn plutôt qu'une réaction indésirable à la mésalazine. En fait, le patient a présenté des améliorations cliniques, radiologiques et fonctionnelles malgré le traitement à la mésalazine et l'abandon de la stéroïdothérapie.
$\mathrm{P}$ ulmonary involvement is uncommon in Crohn's disease (CD) and has been evaluated to occur in $0.4 \%$ of cases (1), a frequency less than that in ulcerative colitis (2). Cases of lung manifestations have been reported in CD, such as granulomatous edema of the upper airways, bronchiectasis, bronchiolitis obliterans organizing pneumonia (BOOP) and lung infiltrates with peripheral eosinophilia (3). Drug therapy for inflammatory bowel disease, such as mesalazine (4), may also cause adverse reactions in the lung and, thus, may present a diagnostic dilemma.

The present report describes the case of a patient with CD who developed diffuse pulmonary infiltrates with hypoxemia two months after administration of oral mesalazine.

\section{CASE PRESENTATION}

A 29-year-old nonsmoking man, who had no history of extraintestinal diseases, was diagnosed with CD by ileocolonoscopy with biopsy in 2001. On October 16, 2002, a relapse of the disease was treated with oral mesalazine $(3 \mathrm{~g} /$ day $)$. On December 14, 2002, the patient suddenly showed dyspnea, a dry cough and fever. Chest x-rays showed the presence of subpleural opacities, predominantly found in the upper right lobe, which were believed to be consistent with infective pneumonia; thus, the patient was treated by his physician with clarithromycin. Because the fever continued, the patient underwent a thoracic computed tomography (CT) scan, which showed the presence of peripheral subpleural opacities in the upper and middle lobes, and less in the left lung. A new trial of antibiotic therapy (levofloxacin $500 \mathrm{mg} /$ day) was initiated. Despite treatment, clinical worsening occurred, and on February 2, 2003, the patient was admitted to hospital with severe pleuritic chest pain, dyspnea at rest, fever (higher than $39^{\circ} \mathrm{C}$ ), abdominal pain and acute bloody diarrhea.

A physical examination of the chest revealed only a respiratory rate of 30 breaths/min and inspiratory crackles at both lung bases. The patient did not present a rash, icterus, hypopigmentation, clubbing, oronasal lesions or eye signs.

Laboratory findings revealed a white blood cell count of $8 \times 10^{9} / \mathrm{L}$ (57\% neutrophils, 26\% lymphocytes and $8.1 \%$ eosinophils), an erythrocyte sedimentation rate of $38 \mathrm{~mm} / \mathrm{h}$ (normal range $0 \mathrm{~mm} / \mathrm{h}$ to $20 \mathrm{~mm} / \mathrm{h}$ ) and a C-reactive protein level of $1.5 \mathrm{mg} / \mathrm{dL}$ (normal range $0 \mathrm{mg} / \mathrm{dL}$ to $0.33 \mathrm{mg} / \mathrm{dL}$ ). Anti-DNA antibodies, circulating immune complexes, antinuclear antibodies and complement levels were all in the normal range. Serology for Mycoplasma pneumoniae, Legionella pneumophila, Chlamydia pneumoniae, Aspergillus fumigatus and Candida albicans were negative. A tuberculin skin test was nonreactive, and sputum stains for Mycobacterium tuberculosis were negative. Arterial blood gas analysis revealed a partial pressure of oxygen of $72 \mathrm{mmHg}(9.5 \mathrm{kPa})$ and a partial pressure of carbon dioxide of $36 \mathrm{mmHg}(4.7 \mathrm{kPa})$ while resting on $2 \mathrm{~L} / \mathrm{min}$ of oxygen. Pulmonary function tests showed a restrictive pattern

${ }^{1}$ Institute of Respiratory Disease, Department of Clinical Methodology and Medical Surgery Technology; ${ }^{2}$ Institute of Pathological Anatomy, University of Bari, Bari, Italy

Correspondence: Dr Onofrio Resta, Department of Clinical Methodology and Medical Surgery Technology, University of Bari, Piazza G Cesare, 11-70124 Bari, Italy. Telephonelfax 39-080-5592907, e-mail oresta@pneumol.uniba.it 


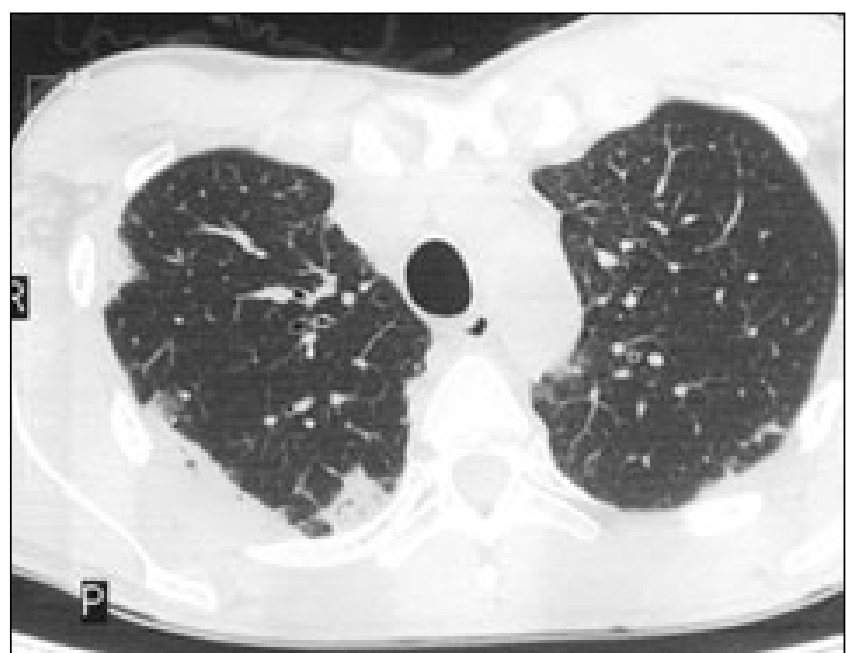

Figure 1) Thorax computed tomography, performed during hospitalization before corticosteroid therapy, showing multiple diffuse, patchy peripheral opacities involving predominantly the upper lobes

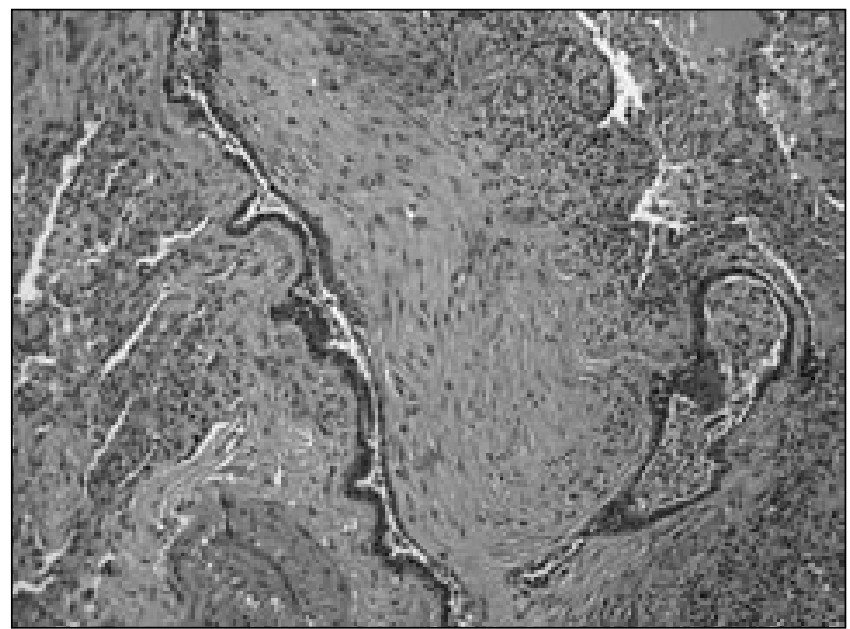

Figure 2) Open-lung biopsy from the right upper lobe showing bronchiolitis obliterans organizing pneumonia. A small muscular pulmonary artery in the lower right quadrant shows severe intimal thickening (hematoxylin and eosin stain, original magnification $\times 400$ )

(forced vital capacity $[\mathrm{FVC}] 53 \%$ of predicted value, forced expiratory volume in $1 \mathrm{~s}\left[\mathrm{FEV}_{1}\right] 42 \%$ of predicted, with a $\mathrm{FEV}_{1} / \mathrm{FVC}$ ratio of $80 \%)$ and a reduced diffusing capacity for carbon monoxide (54\%), with a lung transfer factor for carbon monoxide corrected for hemoglobin to alveolar volume ratio of $99 \%$.

A second CT scan (Figure 1) revealed multiple diffuse, patchy peripheral opacities, predominantly involving the upper lobes, similar to the previous CT scan, and compatible with cryptogenic organizing pneumonia (COP). Fibreoptic bronchoscopy was macroscopically normal. Bronchoalveolar lavage was highly cellular, with $30 \%$ of lymphocytes, an increased CD4 to CD8 ratio (1.8) and a low number of eosinophils (less than $4 \%$ ), similar to previous reports on COP (5). The patient declined transbronchial biopsy and video-assisted thoracoscopy and, eventually, an open-lung biopsy of the right upper lobe was performed. On gross examination, pleurae appeared diffusely inflamed and thickened; a moderate pleural effusion was present and the involved lung was consolidated.

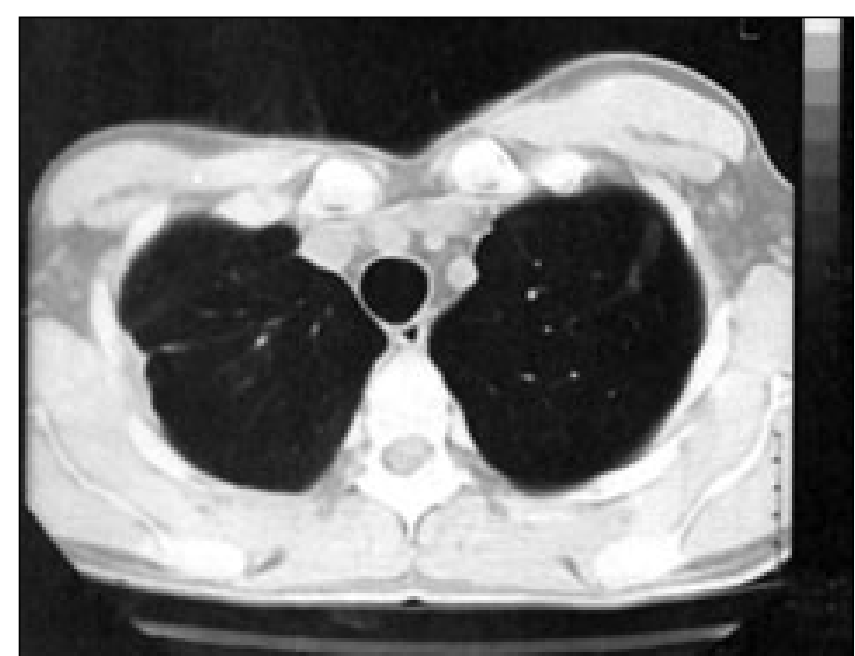

Figure 3) Thorax computed tomography, performed six months after prednisone treatment, showing an almost complete clearing of pulmonary infiltrates

Microscopic examination of lung tissue showed the following findings: atelectasis; mild interstitial collagen fibrosis; isolated foci of nonspecific chronic inflammation bronchiolitis, with non-necrotizing granulomatous inflammation; aspects of myofibroblastic proliferation in the bronchiolar lumen; and the presence of peripheral endoalveolar foamy macrophages (Figure 2). Cultures of the pleural fluid and lung tissue were negative. Histological findings were diagnostic of BOOP, also known as COP.

Treatment was initiated with $40 \mathrm{mg} /$ day intravenous methylprednisolone for two weeks while mesalazine was continued. Clinical, radiological and functional respiratory improvements were observed after eight days of steroid therapy; improvements observed included regression of fever and dyspnea, partial clearing of pulmonary infiltrates, increased partial pressure of oxygen $(81 \mathrm{mmHg}$ [10.68 $\mathrm{kPa}])$, increased FVC (71\%), increased $\mathrm{FEV}_{1}(84 \%)$, an improved $\mathrm{FEV}_{1} / \mathrm{FVC}$ ratio $(97.6 \%)$ and an increased diffusing capacity for carbon monoxide (75\%). After two weeks, the patient was discharged and intravenous corticosteroids were switched to $25 \mathrm{mg} /$ day oral prednisone for two months, and the patient subsequently continued the treatment at a dose of $10 \mathrm{mg} /$ day. Four months later, in the absence of respiratory symptoms, oral prednisone was withdrawn, whereas treatment with oral mesalazine was continued until irritable bowel syndrome improved. Finally, after six months of therapy, the patient was asymptomatic. A third CT scan showed an almost complete clearing of pulmonary infiltrates (Figure 3).

\section{DISCUSSION}

In the present case of pulmonary involvement occurring in $\mathrm{CD}$, the clinical findings, the CT scan abnormalities, the lung histology, the clinical course of pulmonary disease and the response to corticosteroid treatment were strongly suggestive of COP. To our knowledge, few cases of pulmonary parenchymal involvement in patients with $\mathrm{CD}$ have been reported in the literature $(6,7)$, including few cases of BOOP in patients receiving sulfasalazine or mesalamine (3). Although pulmonary involvement may be considered an extraintestinal manifestation of $\mathrm{CD}$, or may be related to treatment with oral 
mesalazine, this is the first case of COP occurring in a patient undergoing treatment for CD.

Sulfasalazine may cause fever, rash, arthralgia, hemolytic anemia (8), and rarely, bilateral patchy lung infiltrates, with or without peripheral eosinophilia (9). Mesalazine is a modified 5-aminosalicylic acid without a sulfonamide group and with less reported sulfonamide-related toxicity. Reactions such as acute interstitial nephritis (10) have been reported in patients taking oral or rectal mesalazine. Pulmonary reactions, including COP, have been reported in patients taking oral or rectal mesalazine (11); however, all cases of COP related to mesalazine were reported in patients affected by ulcerative colitis (12).

In our patient, the following findings were suggestive of pulmonary involvement not related to oral mesalazine: pulmonary

\section{REFERENCES}

1. Rogers BH, Clark LM, Kirsner JB. The epidemiologic and demographic characteristics of inflammatory bowel disease: An analysis of a computerized file of 1400 patients.

J Chronic Dis 1971;24:743-73.

2. Camus P, Piard F, Fur A, et al. [Respiratory manifestations of hemorrhagic rectocolitis]. Rev Mal Respir 1991;8:421-31.

3. Camus P, Piard F, Ashcroft T, Gal AA, Colby TV. The lung in inflammatory bowel disease. Medicine (Baltimore) 1993;72:151-83.

4. Foster RA, Zander DS, Mergo PJ, Valentine JF. Mesalamine-related lung disease: Clinical, radiographic, and pathologic manifestations. Inflamm Bowel Dis 2003;9:308-15.

5. Poletti V, Cazzato S, Minicuci N, Zompatori M, Burzi M, Schiattone ML. The diagnostic value of bronchoalveolar lavage and transbronchial lung biopsy in cryptogenic organizing pneumonia. Eur Respir J 1996;9:2513-6.

6. Casey MB, Tazelaar HD, Myers JL, et al. Noninfectious lung pathology in patients with Crohn's disease. Am J Surg Pathol 2003;27:213-9. manifestations developed in conjunction with the relapse of CD; the absence of pulmonary capillaritis, which is frequently associated with hypersensitivity to the drug; and the patient recovered despite the maintenance of treatment with mesalazine alone for two months. In contrast, other evidence suggests that pulmonary involvement may be related to mesalazine, ie, the development of respiratory manifestations during treatment with mesalazine and the presence of blood and bronchoalveolar lavage eosinophilia.

\section{CONCLUSIONS}

The present findings suggest that $\mathrm{CD}$ may be responsible for the development of COP, probably independent of mesalazine administration; however, further evidence is needed to clarify this pathophysiological mechanism.

7. Asensio Sanchez S, Alba Garcia-Baquero P, Villena V. [Crohn disease and bronchiolitis obliterans organizing pneumonia]. Arch Bronconeumol 1999;35:411-2.

8. Peppercorn MA. Sulfasalazine. Pharmacology, clinical use, toxicity, and related new drug development. Ann Intern Med 1984;101:377-86.

9. Moseley RH, Barwick KW, Dobuler K, DeLuca VA Jr. Sulfasalazine-induced pulmonary disease. Dig Dis Sci 1985;30:901-4.

10. Mehta RP. Acute interstitial nephritis due to 5-aminosalicylic acid. CMAJ 1990;143:1031-2.

11. Mahadeva R, Walsh G, Flower CD, Shneerson JM. Clinical and radiological characteristics of lung disease in inflammatory bowel disease. Eur Respir J 2000;15:41-8.

12. Haralambou G, Teirstein AS, Gil J, Present DH. Bronchiolitis obliterans in a patient with ulcerative colitis receiving mesalamine. Mt Sinai J Med 2001;68:384-8. 


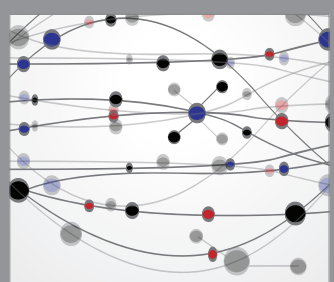

The Scientific World Journal
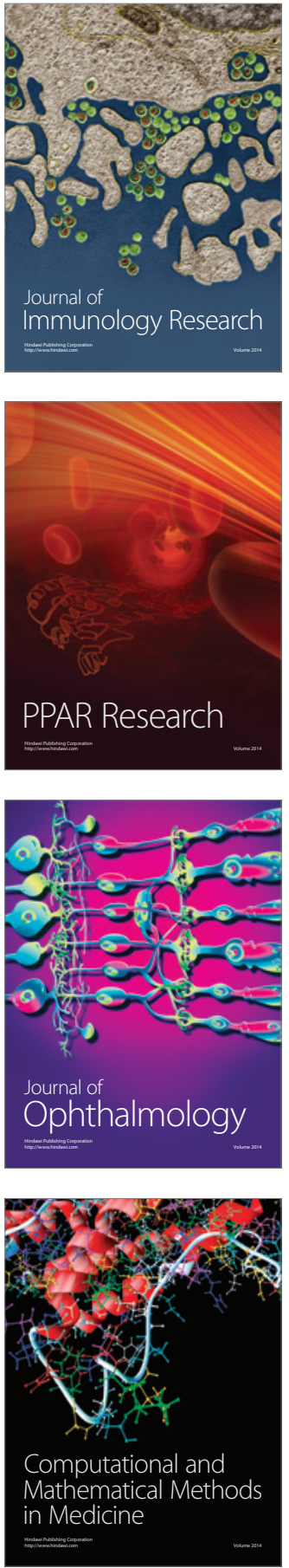

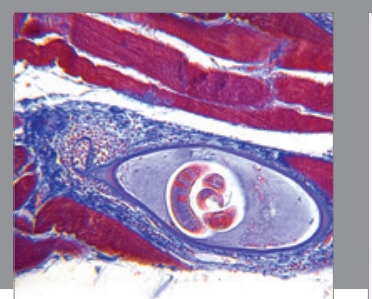

Gastroenterology Research and Practice

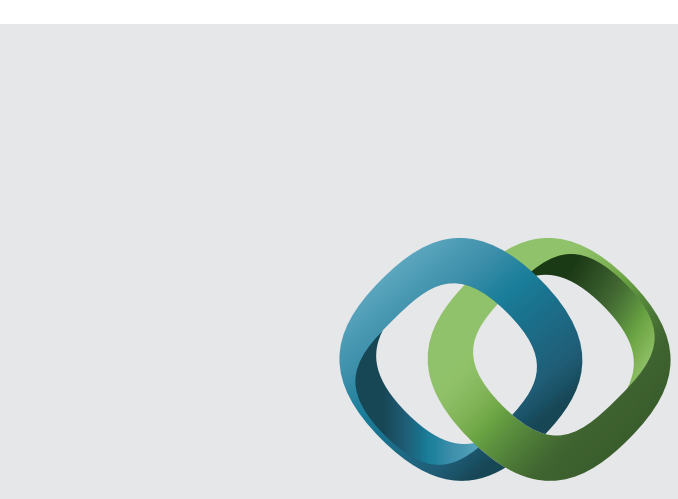

\section{Hindawi}

Submit your manuscripts at

http://www.hindawi.com
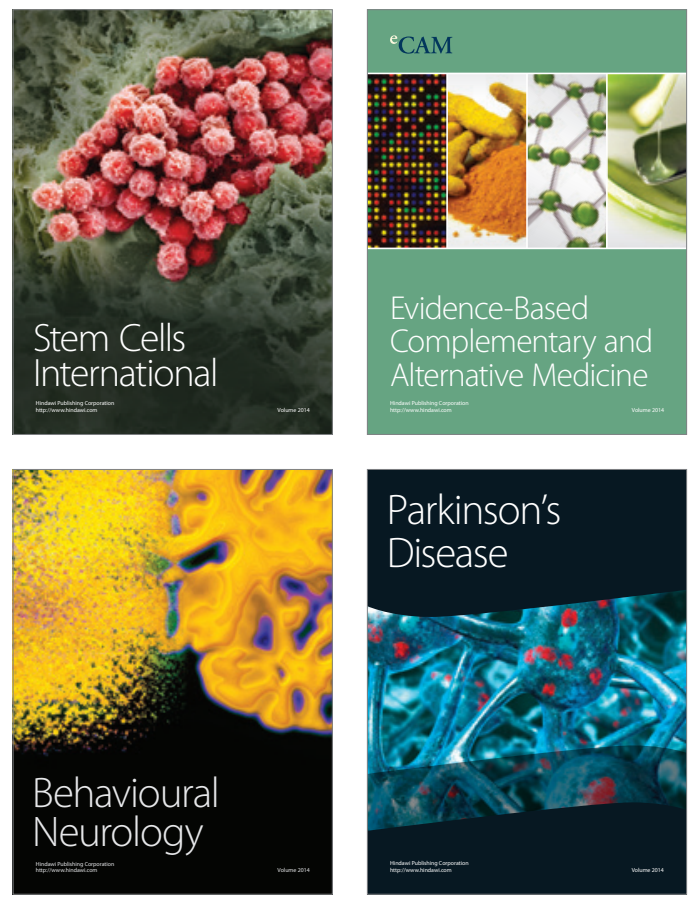
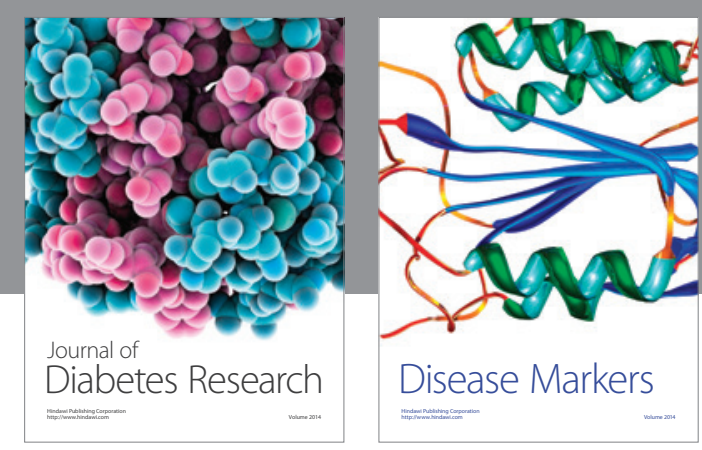

Disease Markers
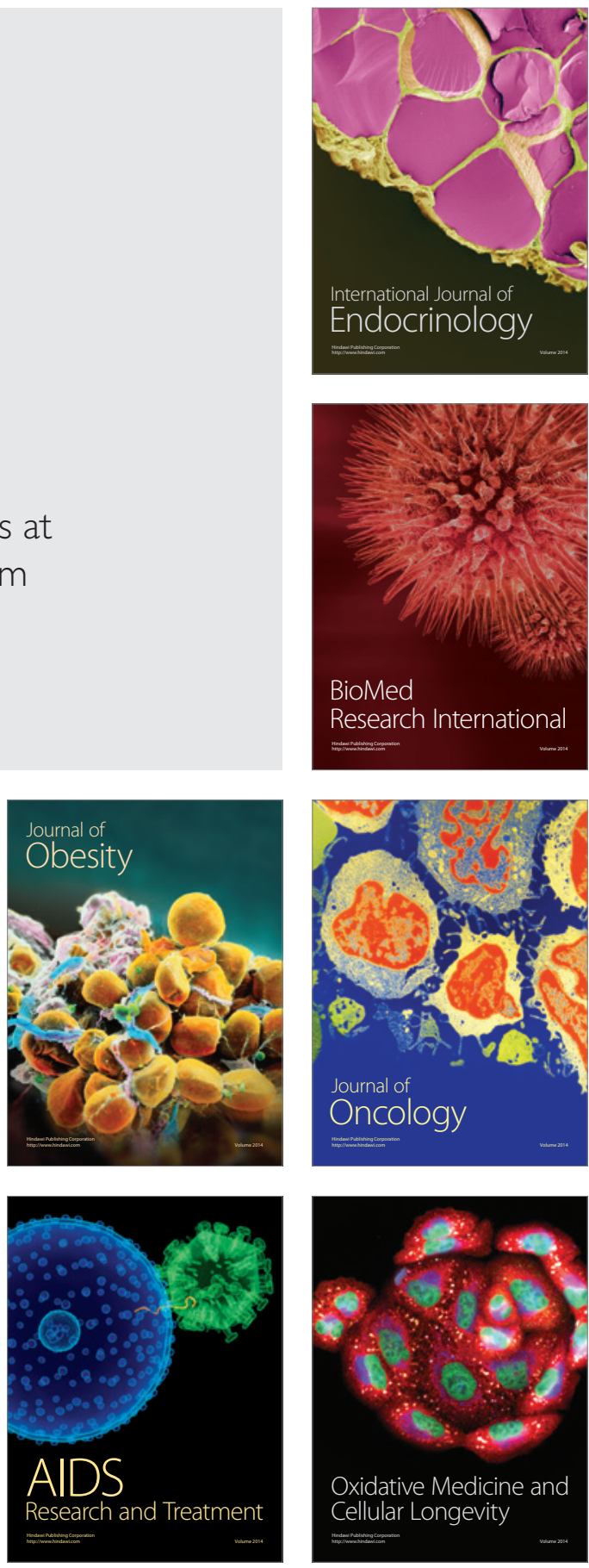